\title{
Lemur Systematics and Hemoglobin Phylogeny ${ }^{a}$
}

\author{
D. H. COPPENHAVER, ${ }^{b}$ P. J. HOPKINS, ${ }^{c}$ \\ M. M. EHRHARDT, ${ }^{d}$ \\ AND L. K. DUFFY ${ }^{d}$ \\ ${ }^{b}$ Department of Microbiology \\ University of Texas Medical Branch \\ Galveston, Texas 77550 \\ ${ }^{c}$ Department of Human Genetics \\ University of Michigan Medical School \\ Ann Arbor, Michigan 48109 \\ ${ }^{d}$ Microsequencing Laboratory \\ Center for Neurologic Research \\ Brigham \& Women's Hospital \\ Boston, Massachusetts 02115
}

There can be only one actual phylogenetic history for any group of organisms. The use of biochemical data is one of several possible means to try to estimate the genetic relationships between organisms. Neontological data, including macromolecular sequences, become particularly relevant in groups with poor or poorly understood fossil records. Hence, we have chosen to study globin evolution in prosimian primates. The dynamics of the evolution of this family of molecules is particularly well suited to contribute to an understanding of prosimian phylogeny. ${ }^{1,2}$

Results of analyses of $\beta$-globin sequences are beginning to produce information bearing on a number of important questions in the phylogeny of prosimian primates. We have determined the amino acid sequences of $\beta$ globins from Lemur catta, ${ }^{2}$ Lemur variegatus, ${ }^{3}$ and Hapalemur griseus (in preparation). These proteins have been analyzed in comparison to the other known prosimian $\beta$-globin sequences: Lemur fulvus, ${ }^{4}$ Nycticebus coucang, ${ }^{5}$ and Loris tardigradus. ${ }^{6}$ The latter two species belong to the superfamily Lorisoidea, while the remaining species belong to the superfamily Lemuroidea. The phenetic distance between the $\beta$-globin sequences for each species is shown in TABLE 1. A number of generalizations are supportable based upon these data. (A) All of the lemuroid sequences are clearly and equally separated from the lorisoid sequences. This is also supported by prosimian $\alpha$-globin data.' (B) As a group the lemuroid sequences are much more divergent from each other than are the lorisoid sequences. (C) Within the Lemuroidea, the $L$. catta and the $L$. variegatus $\beta$ globins are closely related. (D) $H$. griseus $\beta$ globin appears approximately equidistant from the three Lemur sequences. (E) $L$. fulvus, $\beta$ globin, in contrast, shows fewer changes from that of $H$. griseus than it does from the catta/variegatus cluster.

\footnotetext{
${ }^{a}$ Duke University Primate Center Publication No. 404.
} 


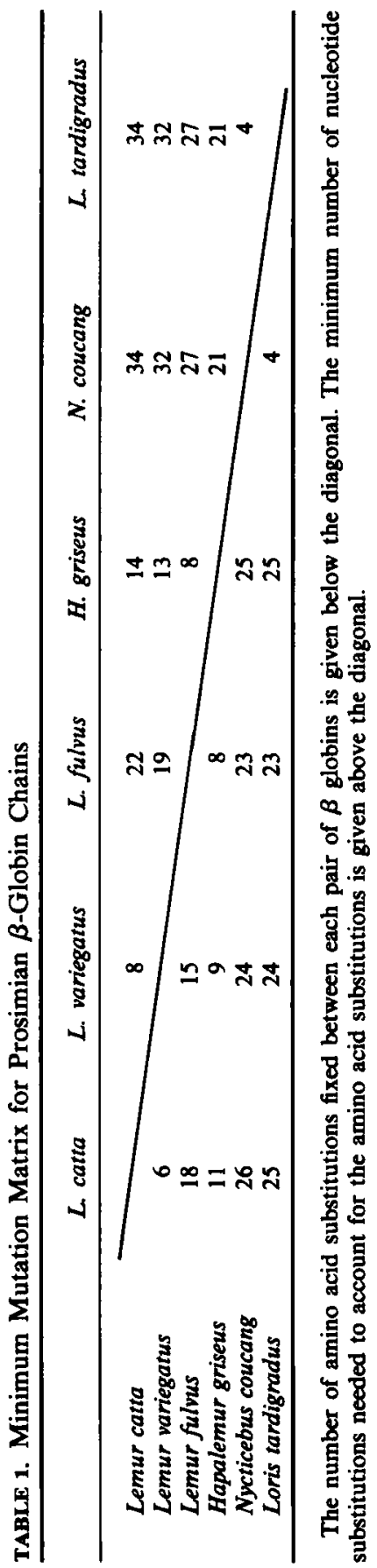


The interpretation of simple substitution matrices derived from sequence data is complicated by the appreciable but variable amount of homoplasy which is hidden in the data. Thus, we analyzed the available sequence data cladistically using a maximum parsimony tree-building procedure. ${ }^{\text {Th }}$ The minimum replacement length solution is shown in FIGURE 1. These data appear robust in that all possible starting branch orders for the lemuroid species produced the same final tree. This reconstruction supports the first three conclusions outlined above, and clarifies the seemingly contradictory statements (D) and (E). $H$. griseus and $L$. fulvus $\beta$ globins are depicted as sharing a common ancestor after the divergence of the catta/variegatus clade. These

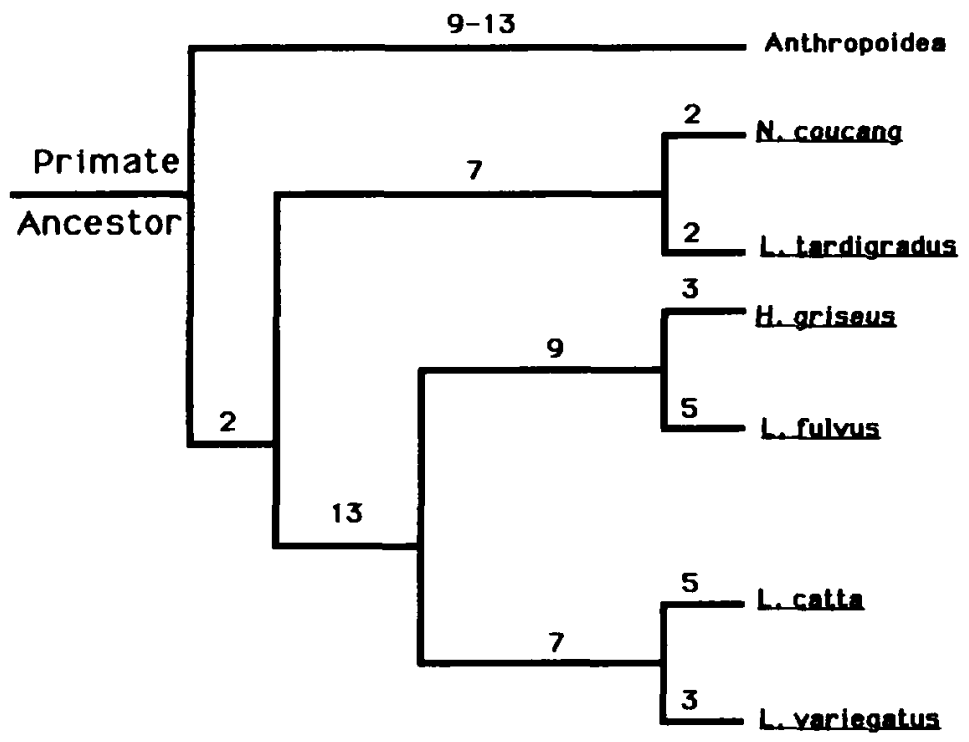

FIGURE 1. Dendrogram of relationships of prosimian $\beta$ globins. The $A$ solution maximum parsimony reconstruction ${ }^{\prime}$ is shown. The dendrogram was rooted using the rabbit $\beta$-globin sequence as the outgroup (not shown). The number of nucleotide substitutions fixed along each branch of the dendrogram is shown. The substitutions shown for the branch leading to higher primates represents the range of substitutions seen using three anthropoid $\beta$-globin sequences: a hominoid (Homo sapiens), a cercopithecoid (Macaca fuscata), and a ceboid (Cebus apella). Owing to the markedly uneven rate of fixation of substitutions in this globin lineage, the branch points should not be used to estimate divergence times for the species shown.

data lend support to the suggestion that reanalysis of the phylogeny of the genus Lemur is needed, ${ }^{3}$ and weigh strongly against the reclassification of variegatus in the monospecific genus "Varecia," while $L$. catta and $L$. fulvus remain congeneric."

Our findings are also relevant to the evolution of the globins. If interpreted strictly according to molecular clock theory, ${ }^{10}$ the evolutionary divergence detected between the four lemuroid species would give unacceptably ancient divergence times for these four species. ${ }^{2,3,9}$ Indeed, examination of the branch lengths in FIGURE 1 shows that lemuroid $\beta$-globin evolution proceeded at 2-3 times the rate detected in either the lorisoid or anthropoid clades, conforming our previous observations of rapid evolution 
of lemuroid $\beta$ globins. ${ }^{2.3 .11-13}$ These data thus provide further compelling evidence that molecular clock theory is inadequate for describing globin evolution. ${ }^{3,8}$ It is unknown at present if gene conversions within the $\beta$-globin complex contributed to the rapid evolution of the lemuroid hemoglobins. The observation that lemur $\beta$-globin sequences show some similarities to higher primate $\delta$ globins ${ }^{11-13}$ along with the finding that the $\delta$ locus in Lemur fulvus is a pseudogene ${ }^{14,15}$ may suggest undetected gene conversions in this evolutionary lineage, producing lemuroid $\boldsymbol{\beta}$ globins which are partially paralogous to the $\beta$ globins of other primates.

\section{REFERENCES}

1. Holmquist, R., T. H. Jukes, M. Goodman \& G. W. Moore. 1976. J. Mol. Biol. 105: 39-74.

2. Coppenhaver, D. H., J. D. Dixon \& L. K. DufFy. 1983. Hemoglobin 7: 1-14.

3. Duffy, L. K. \& D. H. Coppenhaver. 1984. In Hemoglobin. G. Schnek \& C. Paul, Eds. Editions de 1'Universite de Bruxelles. Brussels, Belgium.

4. Marta, T., M. SEToguchi, G. Matsuda \& M. Goodman. 1979. J. Biochem. 85: 755-764.

5. Matsuda, G., T. Maita, B. Watanabe, H. Ota, A. Araya, M. Goodman \& W. Prychodko. 1973. Int. J. Pept. Protein Res. 5: 419-421.

6. Marta, T., M. Goodman \& G. Matsuda. 1978. J. Biochem. 84: 377-383.

7. Duffy, L. K. \& D. H. Coppenhaver. 1984. Ann. N.Y. Acad. Sci. 435: 254-257.

8. Goodman, M. 1981. Prog. Biophys. Mol. Biol. 37: 105-164.

9. Tattersall, I. 1982. The Primates of Madagascar. Columbia University Press. New York.

10. Wilson, A. C., S. S. Carlson \& T. J. White. 1977. Annu. Rev. Biochem. 46: 573-639.

11. Hill, R. L., J. Buettner-JanusCh \& V. Buettner-JanusCh. 1963. Proc. Natl. Acad. Sci. USA 80: 885-893.

12. Hill, R. L. \& J. Buettiner-Janusch. 1964. Fed. Proc. 21: 1236-1242.

13. Buettrner-Janusch, J. 1967. In Neueu Ergebnisse der Primatologie. D. Starck, R. Schneider \& H. J. Kuhn, Eds. G. Fischer Verlag. Stuttgart, FRG.

14. Barrie, P. A., A. J. Jefrreys \& A. F. ScotT. 1981. J. Mol. Biol. 149: 319-336.

15. Jefrreys, A. J., P. A. Barrie, S. harris, D. H. FAWcett, Z. J. Nugent \& A. C. BOYD. 1982. J. Mol. Biol. 156: 487-503. 